Received: $\quad 2018.09 .22$

Accepted: 2018.12.03

Published: 2019.03 .30

\title{
Percutaneous Transforaminal Endoscopic Discectomy versus Micro-Endoscopic Discectomy for Lumbar Disc Herniation
}

Authors' Contribution: Study Design A Data Collection B Statistical Analysis C Data Interpretation D Manuscript Preparation E Literature Search F Funds Collection G

\author{
ABCEF 1 Panfeng Yu \\ BCDE 1 Hua Qiang \\ BCD 1 Jianwei Zhou \\ ADEF 2 Peng Huang
}

1 Department of Orthopedics, Beijing Tongren Hospital, Capital Medical University, Beijing, P.R. China

2 Department of Orthopedics, Chinese PLA General Hospital, Beijing, P.R. China
Corresponding Author: Source of support:
Peng Huang, e-mail: zju001@hotmail.com

Departmental funding from Chinese PLA General Hospital (No. 2016MBD-013)

Background: Percutaneous transforaminal endoscopic discectomy (PTED) and micro-endoscopic discectomy (MED) are alternative minimally invasive, widely performed procedures for the treatment of lumbar disc herniation (LDH). This study compared the clinical outcomes of these 2 surgical techniques in treating LDH.

Material/Methods: A comprehensive literature search was performed in PubMed, MEDLINE, EMBASE, Cochrane, and Google Scholar to identify all relevant studies comparing PTED and MED in treating LDH.

Results: Eight comparative studies assessing a total of 805 patients were included for the final analysis. The results indicated that PTED needs a shorter incision [ $-1.02(-1.21$ to -0.83$), p<0.001]$, less time in bed $[-2.14(-3.34$ to $-0.94), p<0.001]$, and shorter hospital stay [ -1.92 ( -2.90 to -0.94$), p<0.001]$, whereas MED is superior regarding intraoperative fluoroscopy [7.47 (2.78 to 12.17), $p=0.002$ ] and total cost [0.69 (0.38 to 1.00), $p<0.001$ ]. No significant differences were found on operation time, intraoperative blood loss, or complications. Significant lower back pain was found in the PTED group at 1 week postoperatively $[-0.52(-0.95$ to -0.10$), p=0.02]$ and 1 year postoperatively or the last follow-up [ $-0.41(-0.76$ to -0.06$), p=0.02]$; significant lower leg pain was also detected at 1 week postoperatively [ $-0.52(-0.75$ to -0.30$), p<0.001]$. Oswestry Disability Index (ODI) was significant better at 1 week postoperatively in the PTED group [ $-4.41(-7.03$ to -1.79$), p=0.001]$. No significant differences were detected at other time points regarding pain score and ODI.

Conclusions: Both PTED and MED are safe and effective techniques for treating LDH. However, taking all clinical outcomes together, PTED might be a preferable treatment modality for LDH.

MeSH Keywords: Diskectomy, Percutaneous • Lumbosacral Region • Meta-Analysis as Topic

Full-text PDF: https://www.medscimonit.com/abstract/index/idArt/913326

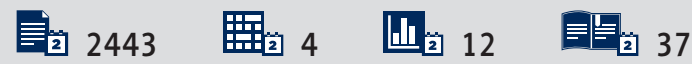




\section{Background}

Lumbar disk herniation (LDH), one of the most common conditions for which patients visit the Department of Orthopedics, always carries a series of signs and symptoms [1]. Lumbosacral radiculopathy caused by the bulge of the nucleus pulposus and the secondary inflammatory reaction is the most challenging problem and often leads to surgical evaluation when conservative management fails [2]. The traditional discectomy through laminotomy and microdiscectomy (MD) have obtained satisfactory results $[3,4]$, but most experienced spine surgeons now prefer use of minimally invasive procedures that cause less trauma and lead to faster rehabilitation, such as percutaneous transforaminal endoscopic discectomy (PTED) and microendoscopic discectomy (MED), which are widely performed in treating LDH and achieve satisfactory clinical outcomes $[5,6]$.

MED, first described by Foley et al. in 1997 [7], uses a microendoscope for visualization and the paraspinous muscles are handled by muscle splitting through dilators, which causes less trauma to the muscle and soft tissue. Numerous studies have confirmed its safety and efficacy, even when treating recurrent LDH $[6,8]$. PTED, introduced by Yeung et al. in 2002 [9], is more minimally invasive, with posterior column lumbar structures preserved. A systematic review and meta-analysis demonstrated that the clinical outcomes are comparable to those achieved using MD [10].

Since the indications for PTED and MED are similar to classical open microdiscectomy when performing surgeries in LDH $[11,12]$, surgeons encounter a dilemma in choosing between these 2 minimally invasive techniques. Many comparative studies were performed to elucidate this issue, but their variable methodologies, small sample sizes, wide confidence intervals, and conflicting results have limited their clinical utility [13-20]. To date, no meta-analysis has been published that resolves this debate. Thus, we conducted the present meta-analysis of all high-quality comparative studies to clarify whether PTED yields better clinical outcomes than MED for treatment of LDH.

\section{Material and Methods}

This meta-analysis was conducted according to the methodological guidelines and recommendations outlined by the Cochrane Collaboration (Oxford, UK) [21]. Data were reported based on the Quality of Reporting of Meta-analyses: the QUOROM statement [22]. We used a checklist to evaluate the quality of the randomized controlled trials (RCTs) [23], and the non-randomized studies (case-control study or cohort study) were evaluated with the Newcastle-Ottawa Scale (NOS) [24] by using a "star system" based on 3 broad perspectives - the selection of the study groups, the comparability of the groups, and the ascertainment of either the exposure or outcome of interest - constituting a total of 9 stars. RCTs and high-quality non-randomized studies ( $\geq 6$ stars) are finally included in the meta-analysis [25].

\section{Inclusion and exclusion criteria}

Eligible studies included in this meta-analysis were required to meet the following inclusion criteria: (1) patients suffering from LDH; (2) high-quality comparative studies reporting the clinical outcomes evaluating PTED and MED procedures; (3) patients were followed for at least 6 months; (4) outcome measurements should include at least 1 of these parameters [Visual Analogue Scale (VAS)score, Oswestry Disability Index (ODI), operation time, blood loss, length of hospital stay and complications]. Exclusion criteria were as follows: (1) abstracts, letters or meeting proceedings; (2) repeated published data; (3) studies including patients who had an intervertebral infection, traumatic fracture, or previous spinal surgery at the same level.

\section{Literature search}

A comprehensive literature search was performed to identify all published comparative studies comparing PTED and MED for the treatment of $\mathrm{LDH}$. Two independent reviewers performed a systematic electronic search of PubMed, MEDLINE, EMBASE, Cochrane Library and Google Scholar from dates of inception to August 31, 2018. Key words used for searching were "lumbar disk herniation", "LDH”, "percutaneous transforaminal endoscopic discectomy", "percutaneous endoscopic discectomy", "transforaminal endoscopic discectomy", "percutaneous discectomy", "micro-endoscopic discectomy", "micro-endoscopic", and "minimally invasive". The search was restricted to articles written in English.

\section{Article selection and validity assessment}

RCTs and high-quality comparative studies comparing PTED and MED were included in this meta-analysis. Inappropriate articles were filtered out by scanning the title of each study. Afterwards, abstracts of remained studies were reviewed by independent reviewers and those were potentially relevant to our study were selected. The reference lists of these articles were further reviewed for any additional studies. We then critically evaluated the studies according to the inclusion and exclusion criteria, evaluated the quality of RCTs by the proposed checklist [23], and assessed non-randomized studies by using NOS [24]. All disagreements were solved by discussion to achieve consensus and further confirmed by a third author. 


\section{Data extraction}

Data on clinical outcomes from individual studies were extracted independently be 2 reviewers and double-checked with the original information to avoid mistakes. Results were reviewed by a senior author; any disagreements were resolved by discussion. Data extracted from each article included study characteristics, participant demographics, sample size, follow-up time, surgical level, operation time, intraoperative blood loss, intraoperative fluoroscopy, incision length, time in bed and hospital stay, total cost, perioperative VAS and ODI, MacNab standard, 36-item Short-Form Health Survey (SF-36), and complications. Among these, the perioperative VAS score and ODI were regarded as primary outcomes.

\section{Statistical analysis}

The meta-analysis was analyzed using Review Manager 5.3 (RevMan 5.3. Ink, Cochrane Collaboration, Oxford, United Kingdom). The $\mathrm{I}^{2}$ statistic [26] (range from 0 to $100 \%$ ) was utilized to quantify heterogeneity between studies. An $1^{2}$ value of $>50 \%$ indicates substantial heterogeneity, and random-effects analysis [27] was used for comparing results with heterogeneity; otherwise a fixed-effects analysis [28] was performed. Continuous variables are reported as mean difference (MD) and $95 \%$ confidence intervals $(\mathrm{Cl})$ such as operation time, and dichotomous variables (e.g., complications) are presented as risk ratios (RR) and $95 \% \mathrm{Cl}$. A p value $<0.05$ was considered to indicate a significant difference.

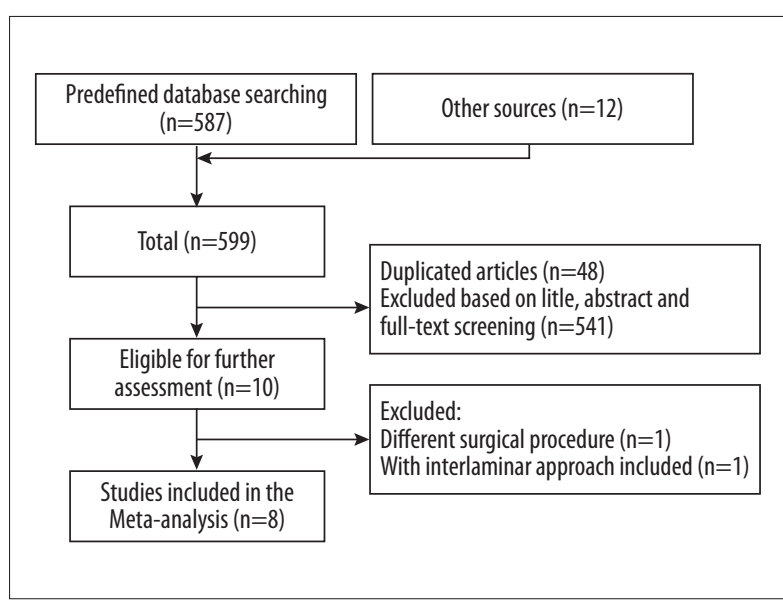

Figure 1. Flow diagram of studies identified in the meta-analysis.

\section{Results}

A flow diagram of the studies identified is shown in Figure 1. Of the 599 studies retrieved by the primary search, 48 were duplicates and 541 studies were excluded based on the titles, abstracts, and full-text screening, leaving 10 potential articles. After critical evaluation, 2 articles were further excluded, of which 1 [29] was excluded because the Teng's automated percutaneous discectomy (APLD) [30] was performed in this study instead of PTED; the other [31] was excluded because some the patients received full-endoscopic interlaminar approach discectomy, which may introduce potential bias to our study. Among the 8 included articles, 1 was an RCT with a CONSORT 20 of a maximum 22 score [14]; the other 7 articles

Table 1. The pooled data of included studies (PTED/MED).

\begin{tabular}{|c|c|c|c|c|c|c|}
\hline Study (year) & Study type & Study quality & Patients & $\begin{array}{l}\text { Average age } \\
\text { (years old) }\end{array}$ & Follow-up time & Surgical level \\
\hline $\begin{array}{l}\text { Abudurexiti T } \\
(2018)[13]\end{array}$ & $\begin{array}{l}\text { Prospective cohort } \\
\text { study }\end{array}$ & NOS 8 stars & $82 / 134$ & $\begin{array}{c}38.2 \pm 9.2 / \\
36.3 \pm 8.6\end{array}$ & $\begin{array}{l}6 \text { months to } \\
2 \text { years }\end{array}$ & $\begin{array}{c}\text { L2-S1 } \\
\text { (mostly L4/L5, L5/S1) }\end{array}$ \\
\hline $\begin{array}{l}\text { Chen Z } \\
(2018)[14]\end{array}$ & $\mathrm{RCT}$ & $\begin{array}{l}\text { CONSORT 20/22 } \\
\text { items }\end{array}$ & $80 / 73$ & $\begin{array}{c}40.2 \pm 11.4 / \\
40.7 \pm 11.1\end{array}$ & 1 year & $\begin{array}{c}\text { L3-S1 } \\
\text { (mostly L4/L5, L5/S1) }\end{array}$ \\
\hline $\begin{array}{l}\text { Liu T } \\
(2012)[15]\end{array}$ & $\begin{array}{l}\text { Retrospective } \\
\text { cohort study }\end{array}$ & NOS 6 stars & $25 / 13$ & $41.5(21-67)$ & 13.5 months & $\begin{array}{c}\mathrm{L} 2-\mathrm{S} 1 \\
\text { (mostly L4/L5, L5/S1) }\end{array}$ \\
\hline $\begin{array}{l}\text { Li H } \\
(2018)[16]\end{array}$ & Case-control study & NOS 8 stars & $48 / 30$ & $\begin{array}{c}19.0 \pm 2.0 / \\
19.4 \pm 1.5\end{array}$ & 5 years & $\begin{array}{c}\mathrm{L3}-\mathrm{S} 1 \\
\text { (mostly L4/L5, L5/S1) }\end{array}$ \\
\hline $\begin{array}{l}\operatorname{Liu} X \\
(2017)[17]\end{array}$ & $\begin{array}{l}\text { Retrospective } \\
\text { cohort study }\end{array}$ & NOS 7 stars & $60 / 63$ & $\begin{array}{c}36.2 \pm 5.9 / \\
33.1 \pm 6.7\end{array}$ & 2 years & $\begin{array}{c}\text { L3-L5 } \\
\text { (mostly L4/L5) }\end{array}$ \\
\hline $\begin{array}{l}\text { Song H } \\
(2017)[18]\end{array}$ & Case-control study & NOS 8 stars & $30 / 30$ & $\begin{array}{c}54.8 \pm 6.5 / \\
53.6 \pm 6.4\end{array}$ & 18 months & $\mathrm{T} 12-\mathrm{S} 1$ \\
\hline $\begin{array}{l}\text { Sinkemani A } \\
(2015)[19]\end{array}$ & Case-control study & NOS 7 stars & $36 / 50$ & $\begin{array}{c}44.2 \pm 6.5 / \\
41.5 \pm 7.2\end{array}$ & 1 year & $\begin{array}{c}\text { L3-S1 } \\
\text { (mostly L4/L5, L5/S1) }\end{array}$ \\
\hline $\begin{array}{l}\text { Yoon S } \\
\text { (2012) [20] }\end{array}$ & $\begin{array}{l}\text { Retrospective } \\
\text { cohort study }\end{array}$ & NOS 6 stars & $25 / 26$ & $\begin{array}{l}45.9(13-70) / \\
56.5(32-79)\end{array}$ & $\begin{array}{l}6 \text { months at } \\
\text { least }\end{array}$ & $\begin{array}{c}\mathrm{L} 1-\mathrm{S} 1 \\
\text { (mostly L4/L5, L5/S1) }\end{array}$ \\
\hline
\end{tabular}

RCT - randomized controlled trial; NOS - Newcastle-Ottawa Scale; CONSORT - Consolidated Standards of Reporting Trials. 


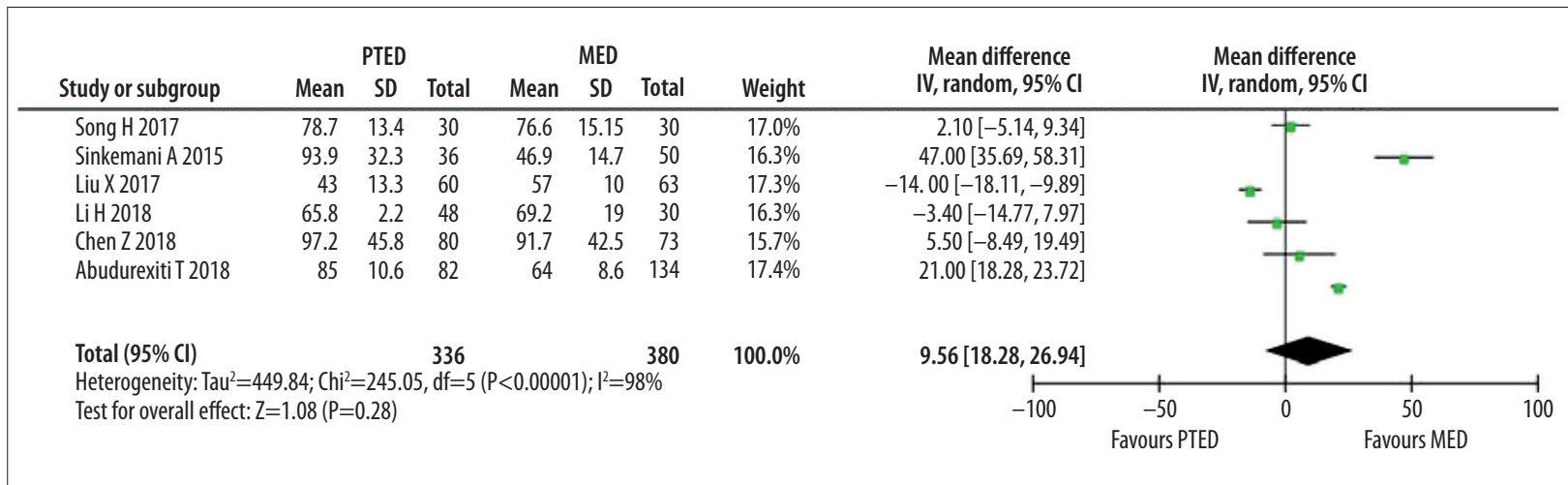

Figure 2. Forest plot of operation time.

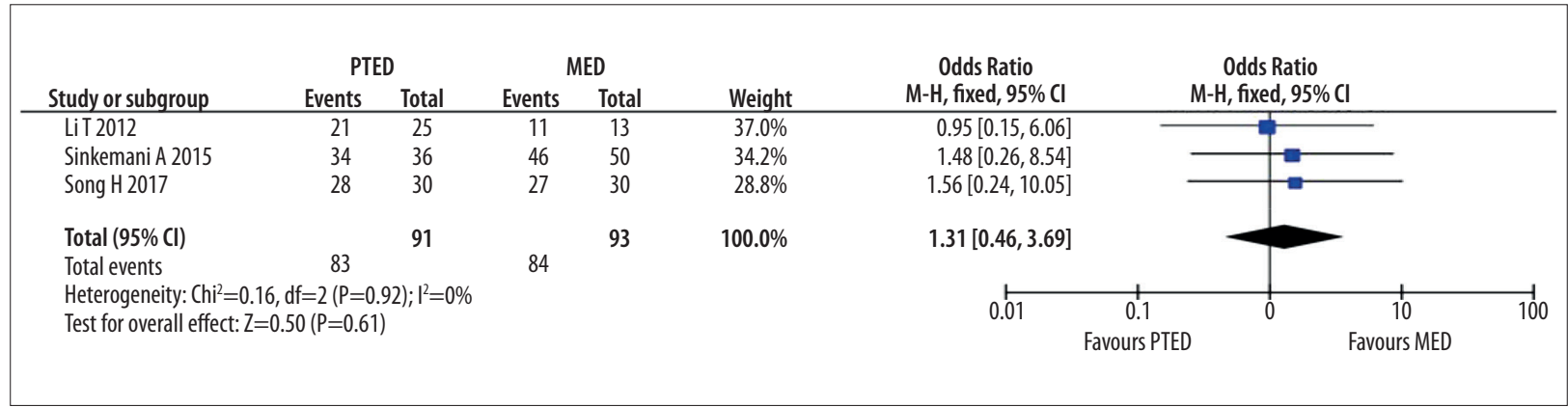

Figure 3. Forest plot of MacNab standard.

Table 2. PTED vs. MED (back pain).

\begin{tabular}{lccc} 
Time points & $\begin{array}{c}\text { No. of } \\
\text { studies }\end{array}$ & $\begin{array}{c}\text { MD } \\
(\mathbf{9 5} \% \mathbf{C l})\end{array}$ & $\begin{array}{c}\mathbf{P} \\
\text { value }\end{array}$ \\
\hline Preoperative & 6 & $\begin{array}{c}0.01 \\
(-0.02 \text { to } 0.23)\end{array}$ & 0.90 \\
\hline 1 week PO & 3 & $\begin{array}{c}-0.52 \\
(-0.95 \text { to }-0.10)\end{array}$ & $0.02^{*}$ \\
\hline 1 month PO & 4 & $\begin{array}{c}-0.11 \\
(-0.51 \text { to } 0.29)\end{array}$ & 0.59 \\
\hline 6 months PO & 3 & $\begin{array}{c}-0.40 \\
(-0.98 \text { to } 0.19)\end{array}$ & 0.19 \\
\hline 1 year PO or & 6 & -0.41 & $0.02 *$ \\
\hline last follow-up & \multicolumn{3}{c}{$(-0.76$ to -0.06$)$} \\
\hline
\end{tabular}

PO - postoperatively; ${ }^{*}$ indicates significant difference.

were observational studies with a NOS $6 \geq$ stars [13,15-20], which were all eligible for the meta-analysis. These studies included a total of 805 patients, 386 of whom constituted the PTED surgical group and the MED intervention group comprised the remaining 419 patients. Table 1 summarizes the characteristics of the 8 included articles.
Table 3. PTED vs. MED (ODI).

\begin{tabular}{|c|c|c|c|}
\hline Time points & $\begin{array}{l}\text { No. of } \\
\text { studies }\end{array}$ & $\begin{array}{c}\text { MD } \\
(95 \% \mathrm{Cl})\end{array}$ & $\begin{array}{c}P \\
\text { value }\end{array}$ \\
\hline Preoperative & 6 & $\begin{array}{c}4.14 \\
(-4.70 \text { to } 12.98)\end{array}$ & 0.36 \\
\hline 1 week PO & 2 & $\begin{array}{c}-4.41 \\
(-7.03 \text { to }-1.79)\end{array}$ & $0.001^{*}$ \\
\hline 1 month PO & 3 & $\begin{array}{c}0.56 \\
(-4.15 \text { to } 5.27)\end{array}$ & 0.82 \\
\hline 6 months PO & 3 & $\begin{array}{c}-1.13 \\
(-3.76 \text { to } 1.49)\end{array}$ & 0.40 \\
\hline $\begin{array}{l}1 \text { year PO or } \\
\text { last follow-up }\end{array}$ & 6 & $\begin{array}{c}-0.27 \\
(-1.71 \text { to } 1.16)\end{array}$ & 0.71 \\
\hline
\end{tabular}

PO - postoperatively; * indicates significant difference.

\section{Outcome analysis}

The results of the meta-analysis for the clinical outcomes are presented in the relevant forest plots and tables (Figures 2, 3, Tables 2, 3).

\section{Perioperative outcome measurements}

We combined the results of 6 studies $[13,14,16,17,19,20]$ in which the hospital stay was stated. A significantly shorter 


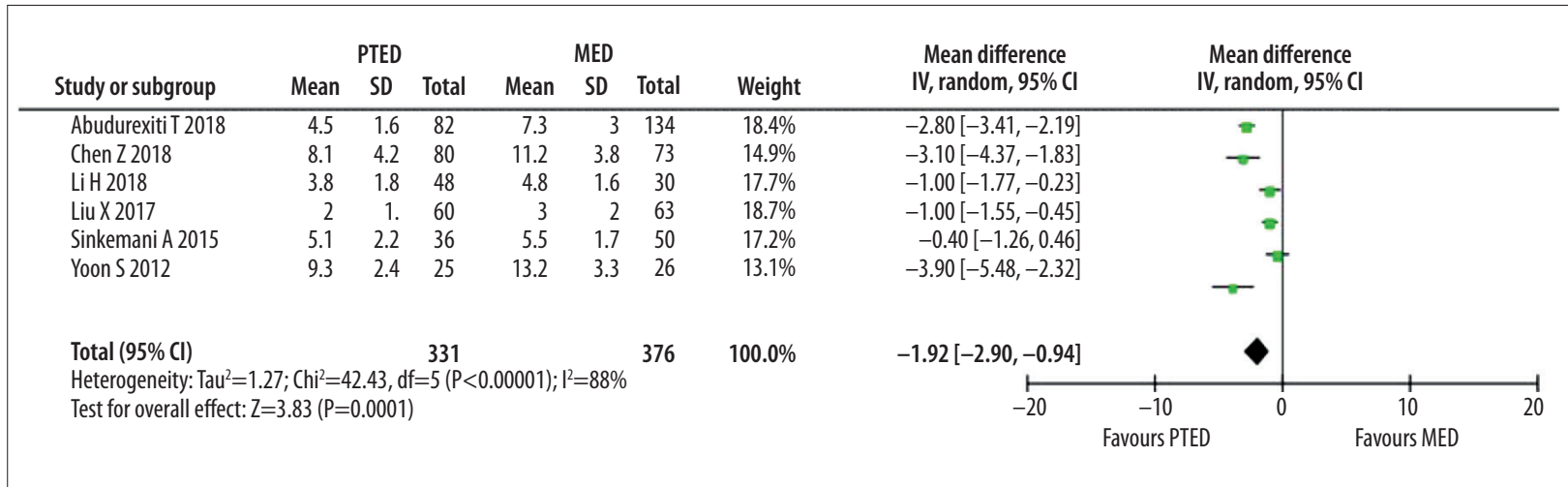

Figure 4. Forest plot of hospital stay.

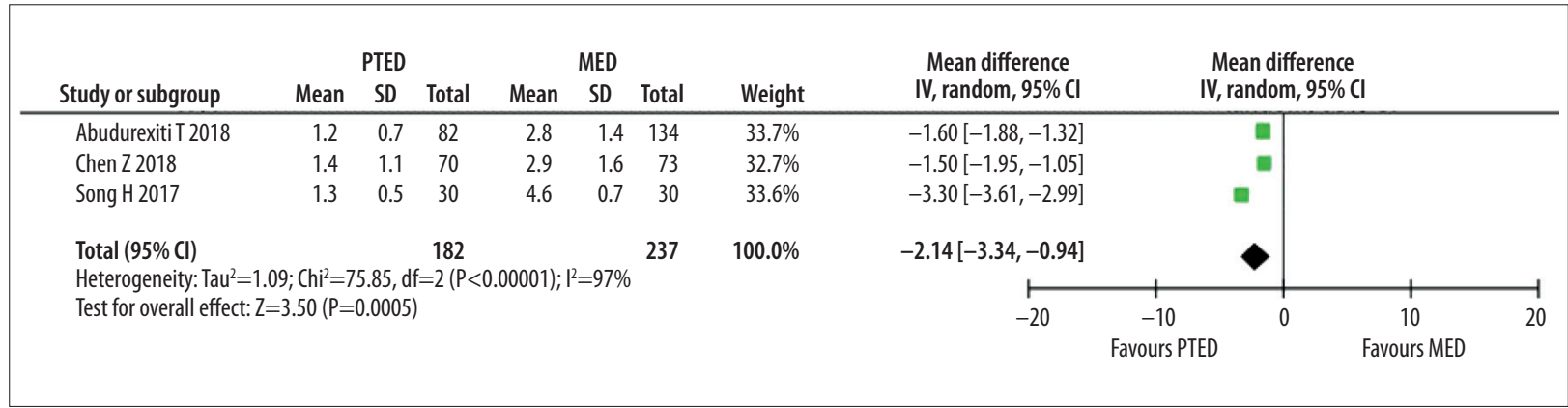

Figure 5. Forest plot of time in bed.

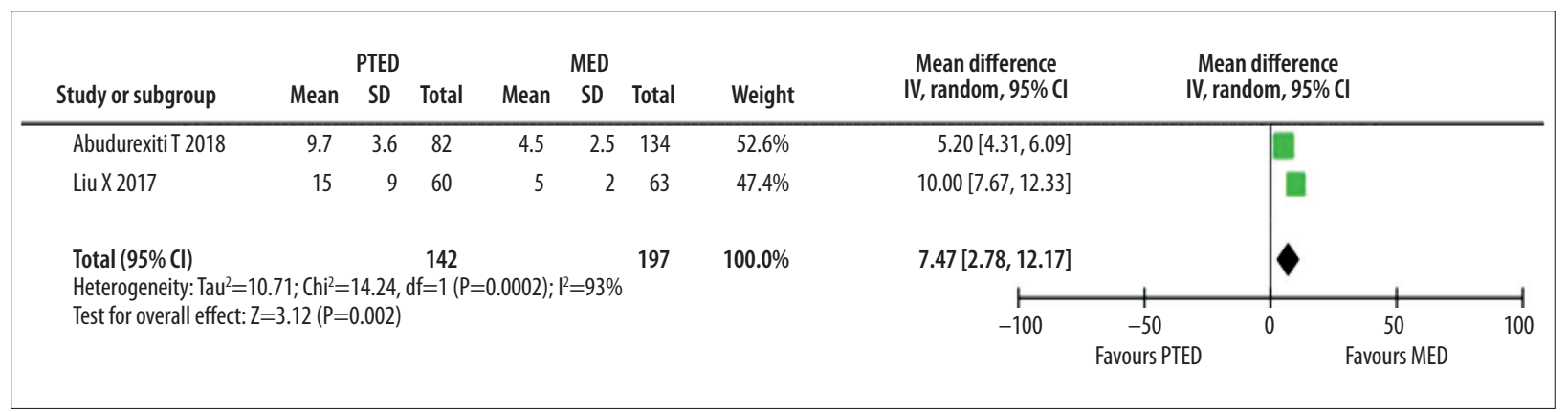

Figure 6. Forest plot of intraoperative fluoroscopy.

time was found in the PTED group ( $p<0.001$, Figure 4). Time in bed was reported in 3 studies $[13,14,18]$, which was also much shorter in the PTED group than in the MED group $(p<0.001$, Figure 5). Intraoperative fluoroscopy was presented in 2 studies $[13,17]$, which indicated a much longer time in the PTED group ( $p=0.002$, Figure 6); another 2 studies [14,19] showed that total cost was significantly higher in the PTED group ( $p<0.001$, Figure 7 ). The incision length was shorter in the PTED group (Figure 8). No significant differences were detected in operation time or intraoperative blood loss (Figures 2, 9).

\section{VAS score and ODI}

A total of 7 studies reported VAS scores during the follow-up time points [13-18,20]; however, 1 study [20] presented the data without standard deviation, so we excluded that study when conducting the analysis. Two studies $[15,18]$ combined back and leg pain, so we used them 2 times when performing the back pain and leg pain analysis separately. Table 2 summarizes the forest plots of the back pain during the followup time points, which indicated that significantly lower VAS scores were found at 1-week postoperatively and 1-year postoperatively or the last follow-up in the PTED treatment group $(p<0.05)$. Table 4 presents the forest plots of the leg pain data, and indicates that VAS score at 1-week postoperatively was significant better in the PTED group ( $p<0.001)$; a trend of better VAS score in the PTED group was detected at 6 months postoperatively $(p=0.07)$. No significant differences were found between groups at other time points. 


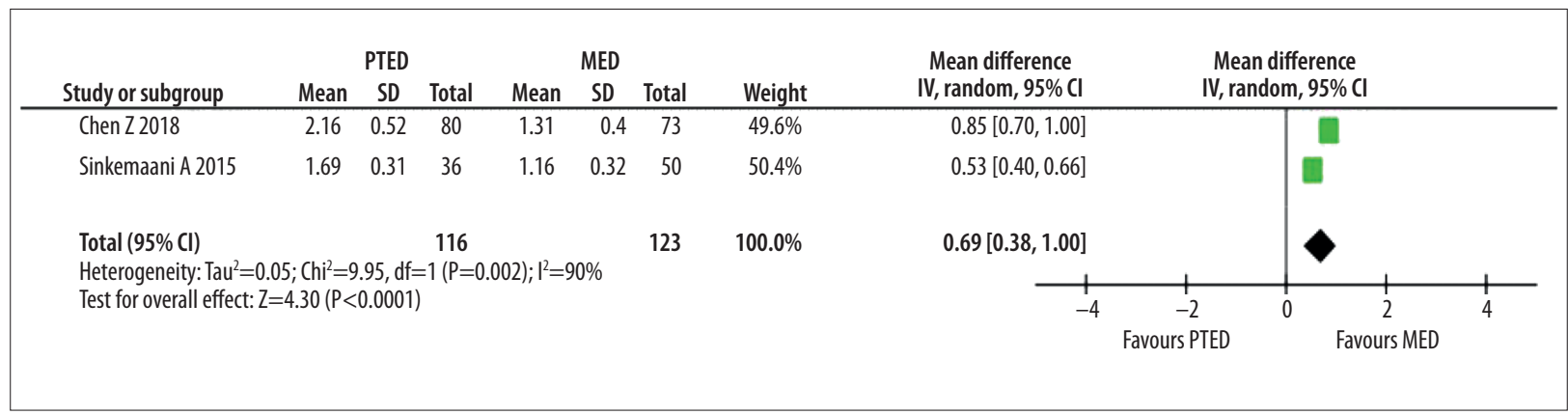

Figure 7. Forest plot of total cost.

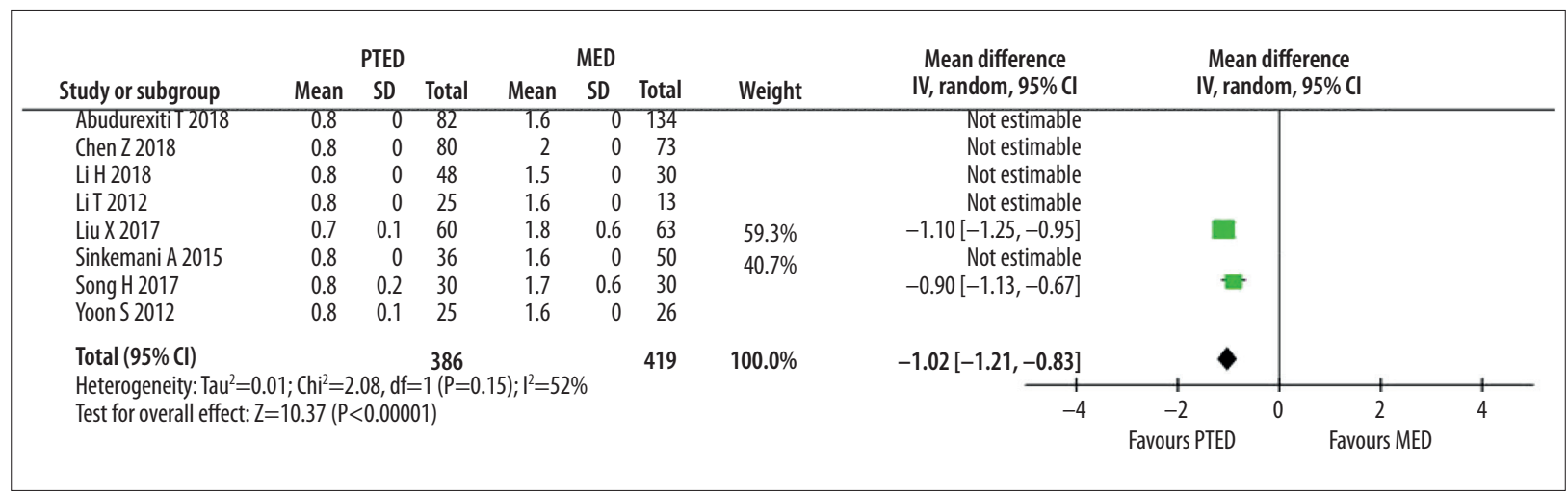

Figure 8. Forest plot of incision length.

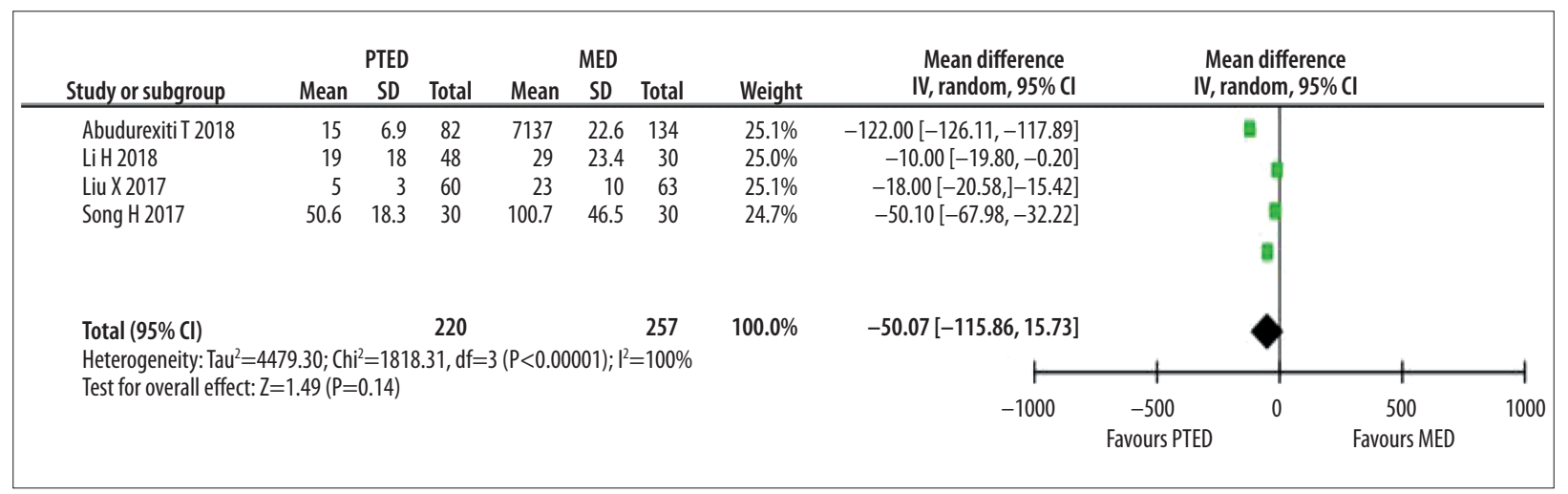

Figure 9. Forest plot of intraoperative blood loss.

Table 4. PTED vs. MED (leg pain).

\begin{tabular}{lccc} 
Time points & $\begin{array}{c}\text { No. of } \\
\text { studies }\end{array}$ & $\begin{array}{c}\text { MD } \\
(\mathbf{9 5 \% C l})\end{array}$ & $\begin{array}{c}\mathbf{P} \\
\text { value }\end{array}$ \\
\hline Preoperative & 6 & $\begin{array}{c}0.08 \\
(-0.14 \text { to } 0.29)\end{array}$ & 0.47 \\
\hline 1 week PO & 3 & $\begin{array}{c}-0.52 \\
(-0.75 \text { to }-0.30)\end{array}$ & $<0.001^{*}$ \\
\hline 1 month PO & 4 & $\begin{array}{c}-0.11 \\
(-0.29 \text { to } 0.07)\end{array}$ & 0.23 \\
\hline
\end{tabular}

\begin{tabular}{lccc}
\hline Time points & $\begin{array}{c}\text { No. of } \\
\text { studies }\end{array}$ & $\begin{array}{c}\text { MD } \\
(\mathbf{9 5 \%} \mathbf{C l})\end{array}$ & $\begin{array}{c}\text { P } \\
\text { value }\end{array}$ \\
\hline 6 months PO & 3 & $\begin{array}{c}-0.16 \\
(-0.33 \text { to } 0.01)\end{array}$ & 0.07 \\
\hline $\begin{array}{l}1 \text { year PO or } \\
\text { last follow-up }\end{array}$ & 6 & $\begin{array}{c}-0.07 \\
(-0.22 \text { to } 0.08)\end{array}$ & 0.38 \\
\hline
\end{tabular}

PO - postoperatively; ${ }^{*}$ indicates significant difference. 


\begin{tabular}{|c|c|c|c|c|c|c|c|c|c|c|}
\hline \multirow[b]{2}{*}{ Study or subgroup } & \multicolumn{2}{|c|}{ PTED } & \multicolumn{2}{|c|}{ MED } & \multirow[b]{2}{*}{ Weight } & \multirow{2}{*}{$\begin{array}{c}\text { Odds ratio } \\
\text { M-H, fixed, } 95 \% \text { Cl }\end{array}$} & \multirow{2}{*}{\multicolumn{2}{|c|}{$\begin{array}{c}\text { Odds ratio } \\
\text { M-H, fixed, } 95 \% \text { Cl }\end{array}$}} & & \\
\hline & Events & Total & Events & Total & & & & & & \\
\hline Abudurexiti T 2018 & 8 & 82 & 11 & 134 & $26.4 \%$ & $1.21[0.47,3.14]$ & & $=-$ & & \\
\hline Chen Z 2018 & 11 & 80 & 12 & 73 & $37.9 \%$ & $0.81[0.33,1.97]$ & & 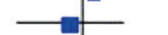 & & \\
\hline LiH 2018 & 1 & 48 & 1 & 30 & $4.2 \%$ & $0.62[0.04,10.25]$ & & & & \\
\hline LiT 2012 & 3 & 25 & 1 & 13 & $4.1 \%$ & $1.64[0.15,17.50]$ & & & & \\
\hline Liu X 2017 & 5 & 60 & 6 & 63 & $18.8 \%$ & $0.86[0.25,2.99]$ & & & & \\
\hline Yoon S 2012 & 4 & 25 & 3 & 26 & $8.7 \%$ & $1.46[0.29,7.30]$ & & & & \\
\hline Total $(95 \%$ Cl) & & 320 & & 339 & $100.0 \%$ & $1.01[0.60,1.69]$ & & & & \\
\hline Total events & 32 & & 34 & & & & & & & \\
\hline $\begin{array}{l}\text { Heterogeneity: } \mathrm{Chi}^{2}= \\
\text { Test for overall effec }\end{array}$ & $\begin{array}{l}\mathrm{f}=5(\mathrm{P}=\mathrm{C} \\
)(\mathrm{P}=0.9\end{array}$ & 7); $I^{2}=0 \%$ & & & & 0.01 & $\begin{array}{c}0.1 \\
\text { Favours PTED }\end{array}$ & 0 & $\begin{array}{c}10 \\
\text { Favours MED }\end{array}$ & 100 \\
\hline
\end{tabular}

Figure 10. Forest plot of total complications.

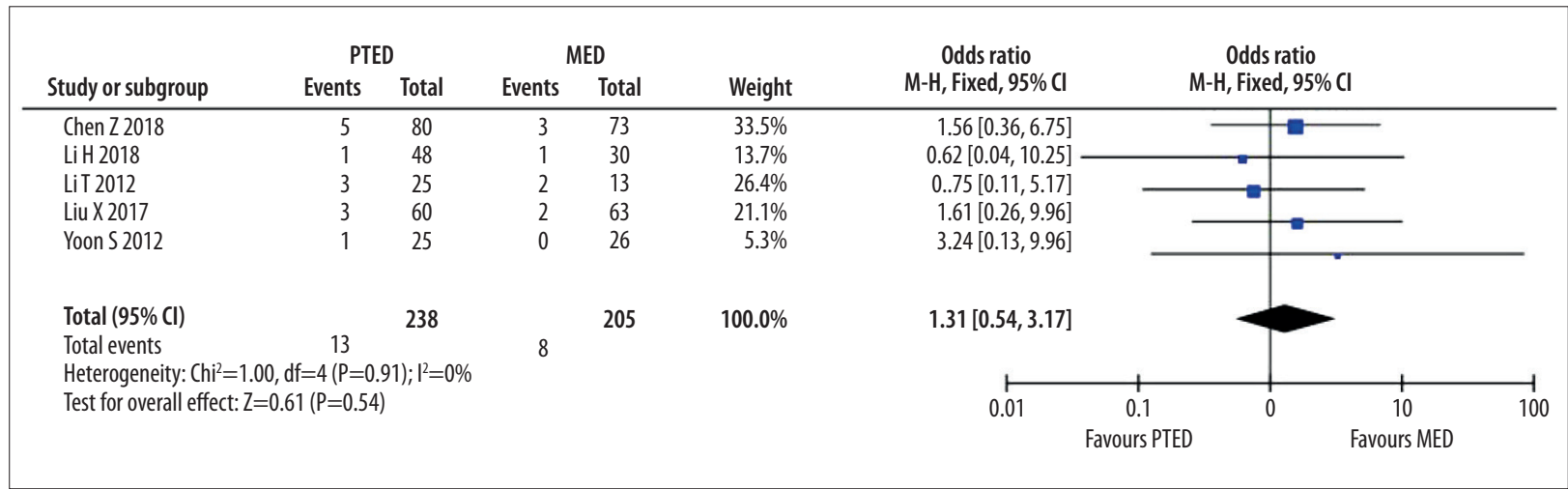

Figure 11. Forest plot of residue or recurrence.

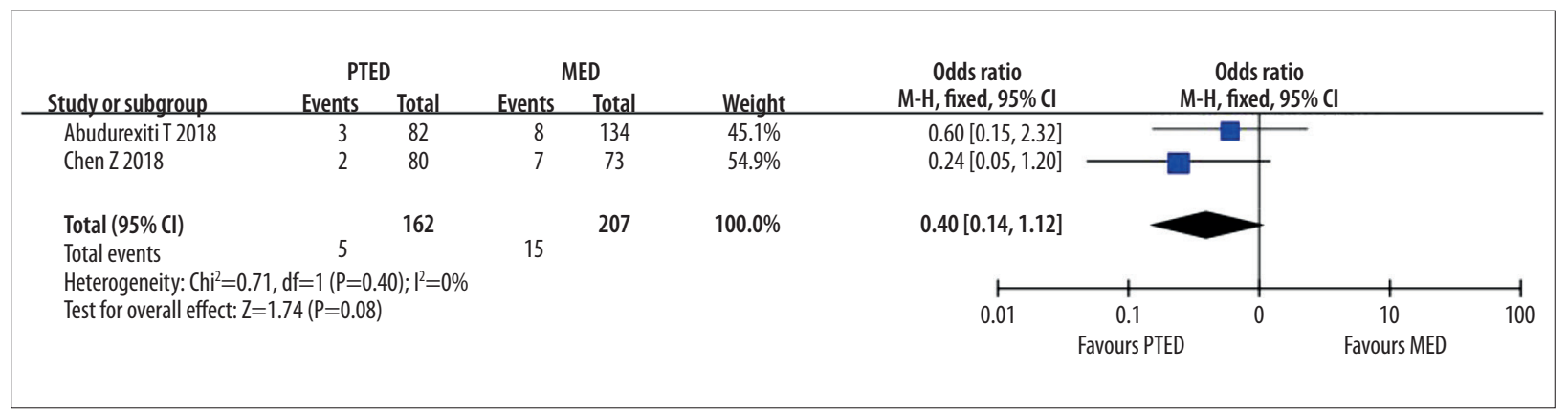

Figure 12. Forest plot of transient dysesthesia.

ODI was reported in 7 studies [13,14,16-20], among which 1 study [20] did not give the standard deviation and was thus excluded when performing analysis. Table 3 summarizes the forest plots of the ODI, showing that significantly lower ODI was detected in the PTED group at 1 week postoperatively $(p=0.001)$, but this should be interpreted with caution as only 2 studies presented data at this time point.

\section{Complications}

Six studies reported detailed complications in their cohorts [13-17,20]; the overall incidence of complications was $10.0 \%(66 / 659)$ and no significant difference was found between groups ( $p=0.98$, Figure 10$)$. Complication of residue or recurrence was revealed in 5 studies [14-17,20], with no significant difference found between groups $(p=0.54$, Figure 11). A trend of transient dysesthesia was detected in 2 studies [13,14], which indicates that this complication was more frequent with the MED technique ( $p=0.08$, Figure 12 ).

\section{Other measurements}

MacNab standard data were reported in 3 studies $[15,18,19]$, and the incidence of excellent and good was 90.8\% (167/184), with no significant difference detected between groups $(p=0.61$, Figure 3). SF-36 scores were reported in 3 studies $[14,19,20]$, 
which was not eligible for meta-analysis, and SF-36 improved satisfactorily from preoperative to the postoperative followup time points. One study [19] demonstrated that the physical function and social function were significantly better in the PTED group than in the MED group $(p=0.016$ and $p=0.016$, respectively).

\section{Discussion}

The findings of the present study indicate that both PTED and MED are safe and effective procedures for treatment of LDH. PTED is associated with shorter time in bed and length of hospital stay, as well as early pain relief and ODI. The PTED technique is associated with higher total costs and the need for intraoperative fluoroscopy. No significant differences were detected regarding operation time, intraoperative blood loss, MacNab standard, or complications. Taking all outcomes together, PTED appears to be the best method for treating LDH.

\section{Perioperative outcome measurements}

Currently, PTED and MED are the most widely performed minimally invasive procedures in treating single-level LDH. MED is carried out based on traditional open surgery and microdiscectomy, and the surgical field is effectively enlarged with the use of a micro-endoscope, which minimizes damage to surrounding tissues $[6,8]$. PTED combines the endoscope and radiofrequency techniques and achieves direct extraction of the protruding disc by a working channel, which has the advantages of minimal invasiveness, less bleeding, easier anesthesia, and faster postoperative recovery $[9,32]$. Due to the differences in the techniques, the incision is usually shorter in the PTED technique, but operation time is similar between groups. In our study, the PTED group recovered faster than the MED group, as shown by time in bed and length of hospital stay. Theoretically, intraoperative blood loss should be less in the PTED group, but due to the high heterogeneity, only a trend was detected. These beneficial factors allowed early ambulation, faster rehabilitation, and a quicker return to daily life activities. However, PTED was associated with a significantly longer intraoperative fluoroscopy due to technical difficulties. PTED had a higher cost due to the need for expensive endoscopic instruments.

\section{VAS score and ODI}

Lower back pain differed between groups at 1 week and 1 year postoperatively and at last follow-up. MED was performed via a posterior approach with an endoscope, and the multifidus was split by dilators [33]. PTED is more minimally invasive because the working channel is smaller and the posterior column structures are preserved [32,34]. Lumbosacral radicular pain is the typical characteristic of LDH [1], and relief of the leg pain is one of the targets of treatment. In our study, significantly less leg pain was detected at 1 week and 6 months postoperatively. As opposed to MED, PTED is performed under persistent saline irrigation. As inflammatory factors are important pathogens in the pathology of $\mathrm{LDH}$, persistent saline irrigation helps clear the inflammatory factors. Furthermore, in the PTED technique, most of the ligamentum flavum (LF) is preserved instead of being fully removed as in the MED technique [14,17]. It has been reported that LF can prevent scar formation and thus help improve clinical outcomes $[35,36]$.

ODI is regarded as one of the primary outcomes widely used to evaluate patients with spinal diseases. It has been demonstrated that ODI is significantly correlated with pain scores [37]. Lower back pain and leg pain were significantly better at 1 week postoperatively in the PTED group, and our ODI results demonstrated that pain scores were significantly better with ODI than with PTED at 1 week postoperatively.

\section{Complications}

In the present study, the incidences of total complications and residue/recurrence were comparable and the MacNab standard results were similar between groups. The findings indicated that although PTED is a more minimally invasive technique, it did not show advantages over MED in terms of complications. However, it is noteworthy that the rate of postoperative transient dysesthesia was much higher in the MED group, but the difference was not significant. This complication is probably due to the traversing of the nerve root and the retraction of the dural sac, which should be performed carefully during surgery to avoid such complications.

\section{Strength and limitations}

Although we attempted to conduct a well-designed meta-analysis, some limitations should be noted: (1) The foremost limitation is the innate flaws of the included studies, including article type, the limited number of studies, and the small sample sizes; (2) The different methodologies contributed to heterogeneity in analyses; (3) Loss of sufficient and usable data makes it difficult to perform accurate analysis of some clinical outcomes; and (4) The skill levels of different surgeons may have introduced bias to the clinical outcomes. Despite these limitations, we believe this is the first meta-analysis to include all comparative studies on this topic. Potential biases may have been minimized by the comprehensive literature search, independent data collection, and critical inclusion and exclusion criteria. 


\section{Conclusions}

This meta-analysis of all available comparative studies provides an overview of current knowledge on PTED versus MED in the treatment of the LDH. Our findings indicate that although differences exist between techniques, both PTED and MED are safe and effective in treating LDH. Taking all outcomes together,

\section{References:}

1. Klineberg E, Ching A, Mundis G et al: Diagnosis, treatment, and complications of adult lumbar disk herniation: Evidence-based data for the healthcare professional. Instr Course Lect, 2015; 64: 405-16

2. Bruggeman AJ, Decker RC: Surgical treatment and outcomes of lumbar radiculopathy. Phys Med Rehabil Clin N Am, 2011; 22(1): 161-77

3. Scholz R, Freiherr SG: [Open lumbar intervertebral disk operation. Technique and results]. Orthopade, 1999; 28(7): 585-92 [in German]

4. Vanni D, Galzio R, Kazakova A et al: Technical note: Microdiscectomy and translaminar approach. J Spine Surg, 2015; 1(1): 44-49

5. Sairyo K, Chikawa T, Nagamachi A: State-of-the-art transforaminal percutaneous endoscopic lumbar surgery under local anesthesia: Discectomy, foraminoplasty, and ventral facetectomy. J Orthop Sci, 2018; 23(2): 229-36

6. He J, Xiao S, Wu Z, Yuan Z: Microendoscopic discectomy versus open discectomy for lumbar disc herniation: A meta-analysis. Eur Spine J, 2016, 25(5): 1373-81

7. Foley KT, Smith MM, Rampersaud YR: Microendoscopic approach to far-lateral lumbar disc herniation. Neurosurg Focus, 1999; 7(5): e5

8. Hubbe U, Francojimenez $\mathrm{P}$, Klingler JH et al: Minimally invasive tubular microdiscectomy for recurrent lumbar disc herniation. J Neurosurg Spine, 2016; 24(1): 48-53

9. Yeung AT, Tsou PM: Posterolateral endoscopic excision for lumbar disc herniation: Surgical technique, outcome, and complications in 307 consecutive cases. Spine, 2002; 27(7): 722-31

10. Kamper SJ, Ostelo RW, Rubinstein SM et al: Minimally invasive surgery for lumbar disc herniation: A systematic review and meta-analysis. Eur Spine J, 2014; 23(5): 1021-43

11. Kambin P, O'Brien E, Zhou L, Schaffer JL: Arthroscopic microdiscectomy and selective fragmentectomy. Clin Orthop Relat Res, 1998; 347(347): 150-67

12. Choi G, Lee $\mathrm{SH}$, Bhanot $A$ et al: Percutaneous endoscopic discectomy for extraforaminal lumbar disc herniations: Extraforaminal targeted fragmentectomy technique using working channel endoscope. Spine, 2007; 32(2): 93-99

13. Abudurexiti T, Qi L, Muheremu A, Amudong A: Micro-endoscopic discectomy versus percutaneous endoscopic surgery for lumbar disk herniation. J Int Med Res, 2018; 46(9): 3910-17

14. Chen Z, Zhang L, Dong J et al: Percutaneous transforaminal endoscopic dis cectomy compared with microendoscopic discectomy for lumbar disc herniation: 1-year results of an ongoing randomized controlled trial. J Neurosurg Spine, 2018: 28: 300-10

15. Liu T, Zhou Y, Wang J et al: Clinical efficacy of three different minimally invasive procedures for far lateral lumbar disc herniation. 2012; 125(6): 1082-88

16. Li H, Li C, Jiang C et al: The comparison of MED and PELD in the treatment of adolescent lumbar disc herniation: A five-year retrospective follow-up. World Neurosurg, 2018; 112: e255-60

17. Liu X, Yuan S, Tian $Y$ et al: Comparison of percutaneous endoscopic transforaminal discectomy, microendoscopic discectomy, and microdiscectomy for symptomatic lumbar disc herniation: minimum 2-year followup results. J Neurosurg Spine, 2018; 28(3): 317-25

18. Song HP, Sheng HF, Xu WX: A case-control study on the treatment of protrusion of lumbar intervertebral disc through PELD and MED. Exp Ther Med, 2017; 14(4): 3708-12
PTED might be a preferable treatment modality for LDH. Further investigation and validation are still required by high-quality prospective randomized controlled studies.

\section{Conflict of interests}

None.

19. Sinkemani A, Hong X, Gao ZX et al: Outcomes of microendoscopic discectomy and percutaneous transforaminal endoscopic discectomy for the treatment of lumbar disc herniation: A comparative retrospective study. Asian Spine J, 2015; 9(6): 833-40

20. Yoon SM, Ahn SS, Kim KH et al: Comparative study of the outcomes of percutaneous endoscopic lumbar discectomy and microscopic lumbar discectomy using the tubular retractor system based on the VAS, ODI, and SF36. Korean J Spine, 2012; 9(3): 215-22

21. Higgins J, Higgins JP: Cochrane handbook for systematic reviews of interventions. Wiley-Blackwell, 2008

22. Moher D, Cook DJ, Eastwood S et al: Improving the quality of reports of meta-analyses of randomised controlled trials: The QUOROM statement QUOROM Group. Onkologie, 2000; 23(6): 597-602

23. Moher D, Schulz KF, Altman DG: The CONSORT statement: Revised rec ommendations for improving the quality of reports of parallel-group randomised trials. Lancet, 2001; 357: 1191-94

24. Wells GA, Shea B, O'Connell D, Rabello A: The Newcastle-Ottawa Scale (NOS) for assessing the quality if nonrandomized studies in meta-analyses. URL http://www.ohri.ca/programs/clinical_epidemiology/oxford.htm

25. Gu WJ, Wang F, Tang L, Liu JC: Single-dose etomidate does not increase mortality in patients with sepsis: A systematic review and meta-analysis of randomized controlled trials and observational studies. Chest, 2015 147(2): 335-46

26. Higgins JP, Thompson SG: Quantifying heterogeneity in a meta-analysis. Stat Med, 2002; 21(11): 1539-58

27. Dersimonian R, Laird N: Meta-analysis in clinical trials. Control Clin Trials, 1986; 7(3): 177-88

28. Lau J, loannidis JP, Schmid CH: Quantitative synthesis in systematic reviews. Ann Intern Med, 1997; 127(9): 820-26

29. Liu WG, Wu XT, Guo JH et al: Long-term outcomes of patients with lumbar disc herniation treated with percutaneous discectomy: Comparative study with microendoscopic discectomy. Cardiovasc Intervent Radiol, 2010; 33(4): 780-86

30. Teng GJ, Jeffery RF, Guo JH et al: Automated percutaneous lumbar discec tomy: A prospective multi-institutional study. J Vasc Interv Radiol, 1997 8(3): 457-63

31. Li M, Yang H, Yang Q: Full-endoscopic technique discectomy versus microendoscopic discectomy for the surgical treatment of lumbar disc herniation. Pain Physician, 2015; 18(4): 359-63

32. Gadjradj PS, Harhangi BS: Percutaneous transforaminal endoscopic discec tomy for lumbar disk herniation. Clin Spine Surg, 2016; 29(9): 368-71

33. Riesenburger RI, David CA: Lumbar microdiscectomy and microendoscopic discectomy. Therapy, 2006; 15(5): 267-70

34. Schubert $M$, Hoogland $\mathrm{T}$ : Endoscopic transforaminal nucleotomy with foraminoplasty for lumbar disk herniation. Oper Orthop Traumatol, 2005; 17(6): 641-61

35. Altun I, Yüksel KZ: Histopathological analysis of ligamentum flavum in lumbar spinal stenosis and disc herniation. Asian Spine J, 2017; 11(1): 71-74

36. Aydin Y, Ziyal IM, Duman $\mathrm{H}$ et al: Clinical and radiological results of lumbar microdiskectomy technique with preserving of ligamentum flavum comparing to the standard microdiskectomy technique. Surg Neurol, 2002; 57(1): 5-13

37. Liu H, Tao H, Luo Z: Validation of the simplified Chinese version of the Oswestry Disability Index. Spine, 2009; 34(11): 1211-16 